\title{
Experimental Study of the Gas Engine Driven Heat Pump with Engine Heat Recovery
}

\author{
Wei Zhang, ${ }^{1}$ Tao Wang, ${ }^{1}$ Sulu Zheng, ${ }^{2}$ Xueyuan Peng, ${ }^{1}$ and Xiaolin Wang ${ }^{3}$ \\ ${ }^{1}$ School of Energy and Power Engineering, Xian Jiaotong University, Xianning West Road 28, Xian 710049, China \\ ${ }^{2}$ Quzhou Centre of Quality Supervision and Technology Testing, 592 Leyuan Road, Quzhou 324002, China \\ ${ }^{3}$ School of Engineering \& ICT, University of Tasmania, Hobart, TAS 7001, Australia
}

Correspondence should be addressed to Xiaolin Wang; xiaolin.wang@utas.edu.au

Received 22 August 2014; Accepted 21 October 2014

Academic Editor: Haochun Zhang

Copyright (C) 2015 Wei Zhang et al. This is an open access article distributed under the Creative Commons Attribution License, which permits unrestricted use, distribution, and reproduction in any medium, provided the original work is properly cited.

\begin{abstract}
Gas engine driven heat pumps (GEHPs) represent one of practical solutions to effectively utilize fossil fuel energy and reduce environmental pollution. In this paper, the performance characteristics of the GEHP were investigated experimentally with engine heat recovery. A GEHP test facility was set up for this purpose. The effects of several important factors including engine speed, ambient temperature, condenser water flow rate, and condenser water inlet temperature on the system performance were studied over a wide range of operating conditions. The results showed that the engine waste heat accounted for about $40-50 \%$ of the total heat capacity over the studied operating conditions. It also showed that engine speed and ambient temperature had significant effects on the GEHP performance. The coefficient of performance (COP) and the primary energy ratio (PER) decreased by $14 \%$ and $12 \%$, respectively, as engine speed increased from $1400 \mathrm{rpm}$ to $2000 \mathrm{rpm}$. On the other hand, the COP and PER of the system increased by $22 \%$ and $16 \%$, respectively, with the ambient temperature increasing from 3 to $12^{\circ} \mathrm{C}$. Furthermore, it was demonstrated that the condenser water flow rate and condenser water inlet temperature had little influence on the COP of the heat pump and the PER of the GEHP system.
\end{abstract}

\section{Introduction}

Improving energy utilization efficiency of thermal processes using fossil fuels is one of the important ways to maintain sustainable economic development and protect the environment of the world. Space and process heating is one of the largest energy consuming sectors. Improvements in energy utilization efficiency of systems in this sector provide a basis for integrating an environmental dimension into energy policy. Heat pumps have been proven to have the best prospects for attaining this goal in a wide variety of appropriate heat applications [1]. Among heat pump systems, GEHPs have been paid more attention in recent years due to their distinguished advantages, such as (1) an ability to recover waste heat released from the engine cylinder jacket and exhaust gas, (2) easy modulation of the engine speed to comply with heat load, and (3) high PER in heating processes.

Many research works have focused on the performance characteristics of GEHPs using theoretical modeling and experimental approaches. Regarding the chronological development of theoretical models for the GEHP system, Zhang et al. [2] developed a steady-state model for an air to water GEHP in heating mode. The engine and compressor models were based on experimental and manufacturer's data, while heat exchanger models were built on mass and energy balance equations. A theoretical heat recovery model was incorporated in the simulation. The results showed that the engine speed has a much larger effect on heat pump performance in comparison to environmental temperature. Based on the mass and energy conservation laws, Shin et al. [3] wrote an algorithm to model the GEHP dynamically in cooling mode. Good agreement with the real system was reached for temperatures, pressures, and system COPs. Yang et al. [4] further reported an intelligent control simulation model for the GEHP in heating mode to predict its dynamic performance. The model was demonstrated to be very effective in analyzing the effect of control parameters. The steadystate accuracy of the intelligent control scheme was higher 
than that of the fuzzy controller which was adopted for the GEHP by Li et al. [5]. Xu and Yang [6] built a theoretical mathematical model in which the waste heat recovered from the engine was used to control year-round room air humidity. The analysis showed that the GEHP could save more energy than the electrical engine heat pump. Sanaye and Chahartaghi [7] developed a theoretical model to predict the performance of the GEHP under different operating conditions. The comparison between simulation results and experimental data showed that the error percentages for suction pressure, discharge pressure, fuel consumption, and system COP were all within $10 \%$, for both cooling and heating modes. Sanaye et al. [8] further combined this model with an economic model in which the economics of the GEHP were analyzed for both residential and commercial buildings in various climate regions of Iran. More recently, Yang et al. [9] developed a thermal model for a GEHP working as a water heater in winter. The model was validated by experimental data. The performance of such a GEHP was analyzed in terms of the COP of the heat pump and PER of the system. The results showed that the water flow rate, hot water temperature, and rotary speed all had an effect on the COP and PER of the system.

As for experimental studies of the GEHP system, Patel et al. [10] compared the performance of a GEHP with R22 and R134a as the primary refrigerants. The test was monitored to determine the energy consumption, cooling capacity, and COP, as well as hours and modes of operation. Furthermore, the energy saving using the GEHP was identified in comparison to the electric driven system. Yang et al. [11] investigated the operating characteristics of a GEHP experimentally under different working conditions. It showed that the GEHP clearly saved energy and the system PER is as high as 1.42. Lazzarin and Noro [12] evaluated the performance of S. Nicola plant in Vicenza during three years of operation. Plant heating load was supplied using a GEHP and two condensing boilers. The GEHP system showed good energy efficiencies and low emissions, although it did not show good economics due to the very low local taxation for natural gas in Italy. Recently, Elgendy and Schmidt [13] experimentally investigated the performance of a GEHP, used in water cooling, without engine heat recovery. It was found that the evaporator water inlet temperature and engine speed substantially affected the PER of the system under the studied operating conditions. Soon after this experiment, Elgendy et al. [14] further studied the performance of a GEHP for hot water supply. This study showed that system PER and total heating capacity increased as the condenser water inlet temperature increased and engine speed decreased. Brenn et al. [15] presented annual efficiencies of a GEHP for building heating and compared GEHP performance with electrically driven heat pump and conventional boiler technologies. The comparison showed that the efficiency of the GEHP was much higher than that of the electrically driven heat pump and about twice that of conventional boiler technologies.

From the above review, some experimental and theoretical investigations on the GEHP system performance are available. However, there is still a lack of experimental data on the GEHP system with engine heat recovery. In this paper, a

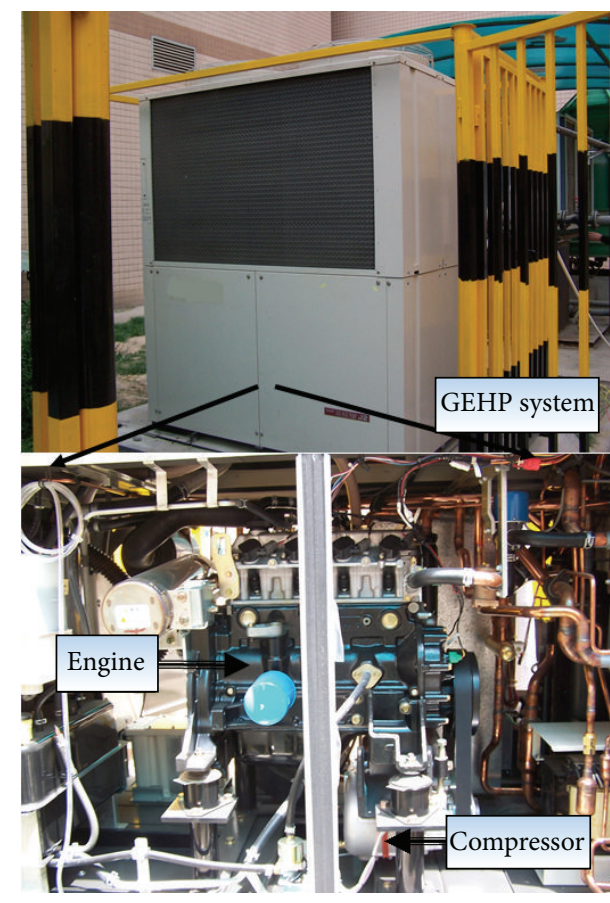

Figure 1: Experimental set-up.

GEHP system test facility with $\mathrm{R} 407 \mathrm{c}$ as a primary refrigerant is constructed and equipped with the necessary instruments. The proportion of engine waste heat to total heat capacity at various operating conditions is analyzed. Furthermore, the effects of engine speed, ambient temperature, condenser water flow rate, and condenser water inlet temperature on the GEHP performance are studied experimentally. The research work provides useful information for system design and energy efficient control strategy.

\section{The Experimental Set-Up and System Description}

Figure 1 shows the experimental set-up of the GEHP system. Schematics with instrumentation points are shown in Figure 2. The system includes a gas engine (Japanese Nissan of nominal heat capacity $39 \mathrm{~kW}$ and nominal speed $1800 \mathrm{rpm}$ ), a sliding vane compressor, a condenser (plate type heat exchanger), an electronic regulating valve, an evaporator, a four-way valve, a waste heat exchanger, an exhaust heat exchanger, two gas-liquid separators, an engine cylinder heat exchanger, a torque meter, operational and safety control devices, and a set of well-insulated pipes. The measurement points are shown in Figure 2. The environmental nonazeotropic refrigerant $\mathrm{R} 407 \mathrm{c}$ was adopted. This apparatus consists of three circuits: a gas supply circuit, heat pump working fluid circuit, and engine coolant circuit.

Heat Pump Working Fluid Circuit. The refrigerant discharged from the compressor (2) enters the condenser (3) where the hot refrigerant exchanges heat with the condenser water. The refrigerant is then cooled and condensed to a subcooled 


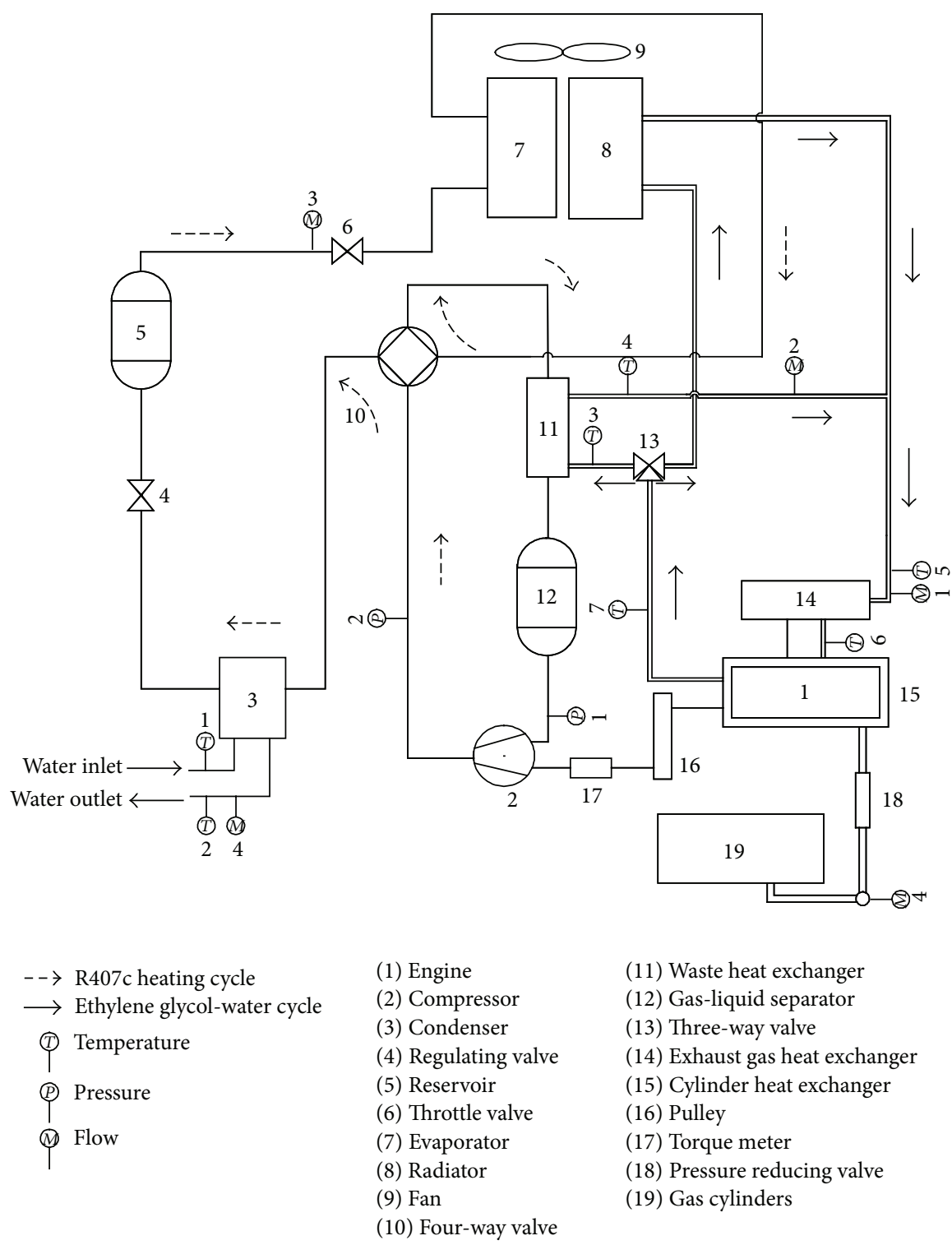

FIGURE 2: Schematic of the experimental apparatus with measuring point locations.

liquid. The liquid refrigerant flows through the electronic expansion valve (6) via the receiver (5) and expands into the evaporator (7) where it absorbs the heat from the ambient air and vaporizes. Afterwards, the refrigerant is channeled into the waste heat recovery exchanger (11) where it further absorbs heat from the engine coolant used to recover heat from the engine cylinder and exhaust gas. Superheated refrigerant enters the accumulator (12) and is sucked by the compressor (2) for the next cycle. In this circuit, the heating capacity of the heat pump is calculated based on the measured condenser water flow rate and the water temperature difference at the condenser inlet and outlet. The compressor power consumption is calculated based on the refrigerant flow rate and the refrigerant specific enthalpy difference across the compressor.

Engine Coolant Circuit. Ethylene glycol-water is used as engine coolant to recover engine waste heat from the exhaust gas heat exchanger (14) and the engine cylinder heat exchanger (15). The coolant flows through the exhaust gas heat exchanger (14) and absorbs heat from the exhaust gas. Afterwards, it is channeled into the engine cylinder where it cools the engine and hence ensures the engine's stable and efficient operation. After the coolant receives the engine waste heat, it is introduced into the heat pump waste heat recovery exchanger (11) where it exchanges energy with the refrigerant from the evaporator and is cooled down for next cycle. The radiator (8) is an auxiliary heat exchanger for engine cooling to prevent the engine coolant temperature from getting too high and hence affect the engine operation. In the engine coolant circuit, the coolant's mass flow rate, the coolant temperatures at the inlet and outlet of the waste heat recovery exchanger (11), the exhaust gas heat exchanger (14), and the engine cylinder are all measured. The heat recovered from the engine cylinder and exhaust 
gas is calculated based on the coolant mass flow rate and temperature differences.

Gas Supply Circuit. The natural gas supply system consists of a set of high pressure gas cylinders (19), pressure reducing valve (18), and a mass flow meter which can measure the natural gas flow rate to evaluate energy consumed by the engine.

The precalibrated PT100 temperature sensors $\left( \pm 0.1^{\circ} \mathrm{C}\right)$ are used to measure operating temperatures, while MPM480 digital pressure sensors $( \pm 0.2 \%$ of full scale, $0-3.5 \mathrm{MPa})$ are used to record the operating pressures at the measurement points in the refrigeration circuit of the heat pump, as shown in Figure 2. The mass flow rate of refrigerant is measured using the mass flow meter, LWGYC-10, with an accuracy $\pm 0.5 \%$ of full scale $\left(0.2-1.2 \mathrm{~m}^{3} / \mathrm{h}\right)$, while the electromagnetic flow meter, ZHLD-25 (with accuracy $\pm 0.5 \%$ of full scale, $0.3-$ $12 \mathrm{~m}^{3} / \mathrm{h}$ ), is used to measure the engine coolant. LDBE-40S (with accuracy $\pm 0.5 \%$ of full scale, $0.3-12 \mathrm{~m}^{3} / \mathrm{h}$ ) is used to measure the condenser water flow rate. The natural gas flow rate is measured by the mass flow meter DMF-1-1 with an accuracy $\pm 0.2 \%$ of full scale $(0-15 \mathrm{~kg} / \mathrm{h})$. All the measured data are recorded in the computer over time, and the measurement locations are marked as T, p, and M for temperature, pressure, and flow rate, respectively, as shown in Figure 2.

\section{Data Reduction and Error Analysis}

3.1. Performance Calculation. Measured data for R407c operating pressures and temperatures, as well as ethylene glycolwater and condenser water temperatures, can be used to determine the specific enthalpy values at the inlet and outlet of each component. Then the energy and mass balance calculations can be carried out for the main components of the gas engine driven heat pump, thus enabling the GEHP system performance to be determined from the measured flow rate data.

The heating capacity $\dot{Q}_{h}$ is calculated based on the condenser water flow circuit as follows:

$$
\dot{Q}_{h}=\dot{m}_{w, c} \cdot c_{p, w, c} \cdot \Delta T_{w, c},
$$

where $\dot{m}_{w, c}$ is condenser water flow rate, $c_{p, w, c}$ is specific heat of condenser water at constant pressure, and $\Delta T_{w, c}$ is water temperature difference at the condenser inlet and outlet.

The heat $\dot{Q}_{\text {exh }}$ recovered from the engine cylinder and exhaust gas is calculated based on the ethylene glycol-water flowing in the waste heat recovery exchanger as follows:

$$
\dot{Q}_{\text {exh }}=\dot{m}_{g w, \text { exh }} \cdot c_{p, \text { exh }} \cdot \Delta T_{g w, \text { exh }}
$$

where $\dot{m}_{g w \text {,exh }}$ is ethylene glycol-water flow rate, $c_{p \text {,exh }}$ is specific heat of ethylene glycol-water at constant pressure, and $\Delta T_{g w \text {,exh }}$ is ethylene glycol-water temperature difference at the inlet and outlet of the waste heat recovery exchanger.

The fraction $\eta_{\text {exh }}$ of the recovered waste heat $\dot{Q}_{\text {exh }}$ to the total heat capacity $\dot{Q}_{h}$ is then calculated by

$$
\eta_{\mathrm{exh}}=\frac{\dot{\mathrm{Q}}_{\mathrm{exh}}}{\dot{\mathrm{Q}}_{h}} .
$$

The compressor power $W_{\text {comp }}$ is calculated based on the specific enthalpy of the refrigerant at the compressor inlet and outlet:

$$
\begin{aligned}
W_{\text {comp }} & =\dot{m}_{\text {ref }} \cdot \frac{\left(h_{\text {ref,out }}-h_{\text {ref,in }}\right)}{\eta_{\text {comp }}}, \\
h_{\text {ref,out }} & =f\left(P_{\text {comp ,out }}, T_{\text {comp ,out }}\right), \\
h_{\text {ref,in }} & =f\left(P_{\text {comp ,in }}, T_{\text {comp ,in }}\right),
\end{aligned}
$$

where $\dot{m}_{\text {ref }}$ refers to refrigerant flow rate and $h_{\text {ref,in }}$ and $h_{\text {ref,out }}$ refer to refrigerant specific enthalpy at the compressor inlet and outlet, respectively. $P_{\text {comp ,in }}, P_{\text {comp ,out }} T_{\text {comp, in }}$, and $T$ comp ,out are the pressures and temperatures at the compressor inlet and outlet. The specific enthalpy is obtained from the NIST data base according to the temperature and pressure. $\eta_{\text {comp }}$ is compressor mechanical efficiency (0.96).

The total energy consumption $\dot{E}_{\text {ng }}$ is calculated based on the natural gas flow rate $\dot{m}_{\text {ng }}$ and low heating value, LHV, as follows:

$$
\dot{E}_{\mathrm{ng}}=\dot{m}_{\mathrm{ng}} \cdot \mathrm{LHV} \text {. }
$$

The COP of the heat pump and the PER of the GEHP system are then calculated by

$$
\begin{gathered}
\text { COP }=\frac{\dot{Q}_{h}}{W_{\text {comp }}}, \\
\text { PER }=\frac{\dot{Q}_{h}}{\dot{E}_{\mathrm{ng}}} .
\end{gathered}
$$

3.2. Error Analysis. According to Gaussian law of error propagation, the overall relative error $\left(e_{x}\right)$ of a quantity $x$ indirectly evaluated from the measured values of the variable $x_{i}^{\text {meas }}$ can be calculated by

$$
e_{x}= \pm \sqrt{\sum_{i=1}^{n} e_{i}^{2}\left(x_{i}^{\mathrm{meas}}\right)}
$$

Using (7), the overall relative errors $e_{\dot{\mathrm{Q}}_{h}}, e_{\mathrm{Q}_{\mathrm{exh}}}, e_{W_{\text {comp }}}, e_{\mathrm{COP}}$, $e_{\text {PER }}$ of $\dot{Q}_{h}, \dot{Q}_{\text {exh }}, W_{\text {comp }}$, COP, and PER are calculated as follows:

$$
\begin{gathered}
e_{\dot{\mathrm{Q}}_{h}}= \pm \sqrt{e_{\dot{m}_{w, c}}^{2}+e_{\Delta T_{w, c}}^{2}}, \\
e_{W_{\mathrm{comp}}}= \pm \sqrt{e_{\dot{m}_{\mathrm{ref}}}^{2}+e_{\Delta h_{\mathrm{ref}}}^{2}}, \\
e_{\dot{E}_{\mathrm{ng}}}= \pm \sqrt{e_{\dot{m}_{\mathrm{ng}}}^{2}}= \pm e_{\dot{m}_{\mathrm{ng}}}, \\
e_{\dot{\mathrm{Q}}_{\mathrm{exh}}}= \pm \sqrt{e_{\dot{m}_{w, \mathrm{exh}}}^{2}+e_{\Delta T_{w, \mathrm{exh}}}^{2}}, \\
e_{\mathrm{COP}}= \pm \sqrt{e_{\dot{\mathrm{Q}}_{h}}^{2}+e_{W_{\mathrm{comp}}}^{2}}, \\
e_{\mathrm{PER}}= \pm \sqrt{e_{\dot{\mathrm{Q}}_{h}}^{2}+e_{\dot{E}_{\mathrm{ng}}}^{2}},
\end{gathered}
$$




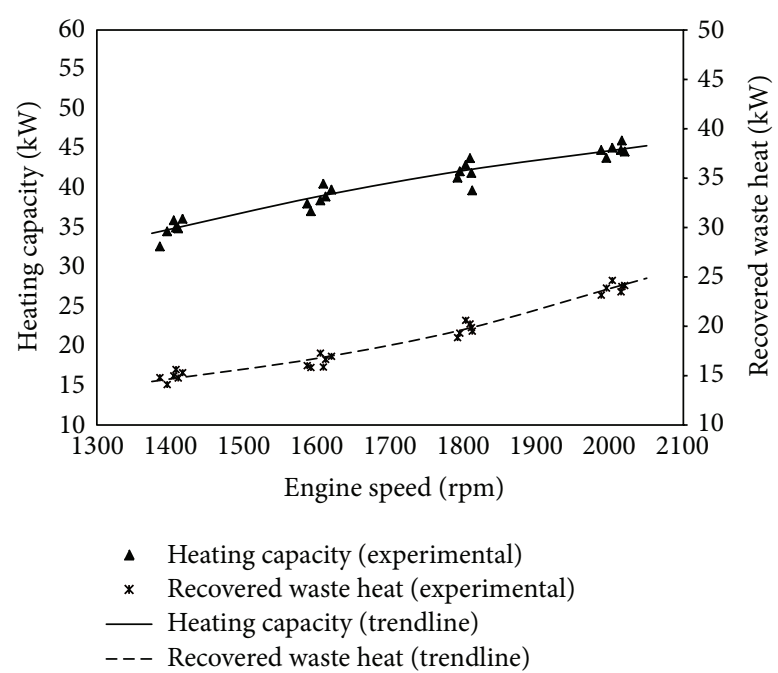

FIGURE 3: Heating capacity and recovered waste heat versus engine speed.

where $e_{\dot{m}_{w, c}}$ is the relative error of condenser water flow rate measurements $( \pm 1.8 \%), e_{\Delta T_{w, c}}$ is the relative error of condenser water temperature difference measurements $( \pm 2.8 \%)$, $e_{\dot{m}_{\text {ref }}}$ is the relative error of refrigerant flow rate measurements $( \pm 1 \%), e_{\Delta h_{\text {ref }}}$ represents the relative error of refrigerant specific enthalpy difference resulting from error of pressure and temperature measurements and is $\pm 1.8 \%, e_{\dot{m}_{\mathrm{ng}}}$ is the relative error of natural gas flow rate measurements $( \pm 1.3 \%), e_{\dot{m}_{w, \text { exh }}}$ is the relative error of ethylene glycol-water flow rate measurements $( \pm 7 \%)$, and $e_{\Delta T_{w, e x h}}$ is the relative error of ethylene glycol-water temperature difference measurements (2.6\%).

Therefore, the overall relative errors for $\dot{Q}_{h}, \dot{Q}_{\text {exh }}$, COP, and PER are $\pm 3.3 \%, \pm 7.5 \%, \pm 3.5 \%$, and $\pm 3.4 \%$, respectively.

\section{Results and Discussion}

The performance characteristics of the GEHP system were studied under different operating conditions, and the effects of key operating parameters on the system heat capacity, heat pump COP, and system PER were investigated. In order to minimize the measurement error, the experiments were repeated four times at each operating condition. The second order polynomial trend was used to fit the experimental data to analyze the effect of the operating parameters on the GEHP system performance. Table 1 listed the GEHP experimental operating conditions in this study.

4.1. Effect of Engine Speed. One of the GEHP system advantages is that engine speed can be adjusted easily to comply with the heat load. Hence it is important to understand the effect of engine speed on the system performance.

Figures 3-5 presented the GEHP system performance at different engine speeds. Figure 3 showed that both the heating capacity and the recovered waste heat increased sharply with increasing the engine speed. With the engine speed increasing from $1400 \mathrm{rpm}$ to $1600 \mathrm{rpm}, 1800 \mathrm{rpm}$ and $2000 \mathrm{rpm}$, the

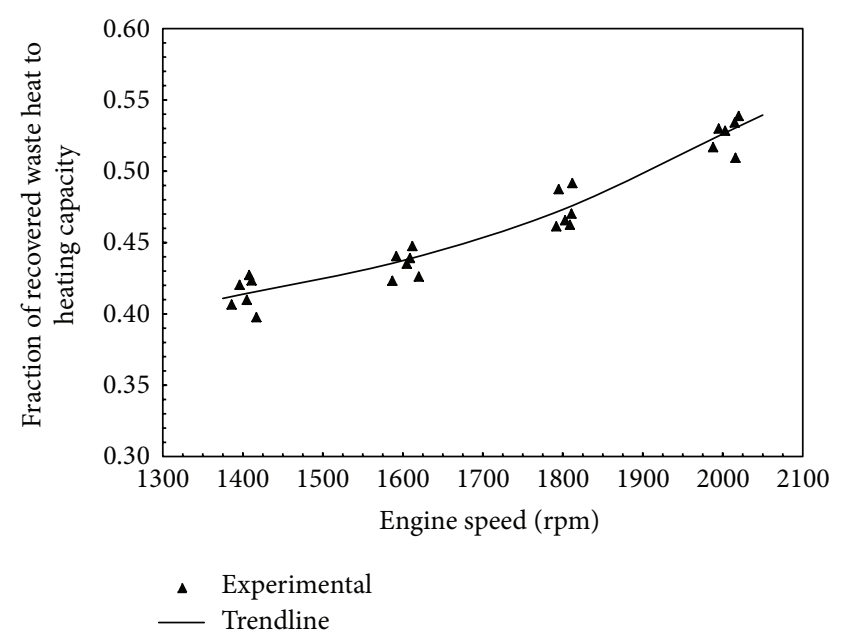

FIGURE 4: Fraction of recovered waste heat to heating capacity versus engine speed.

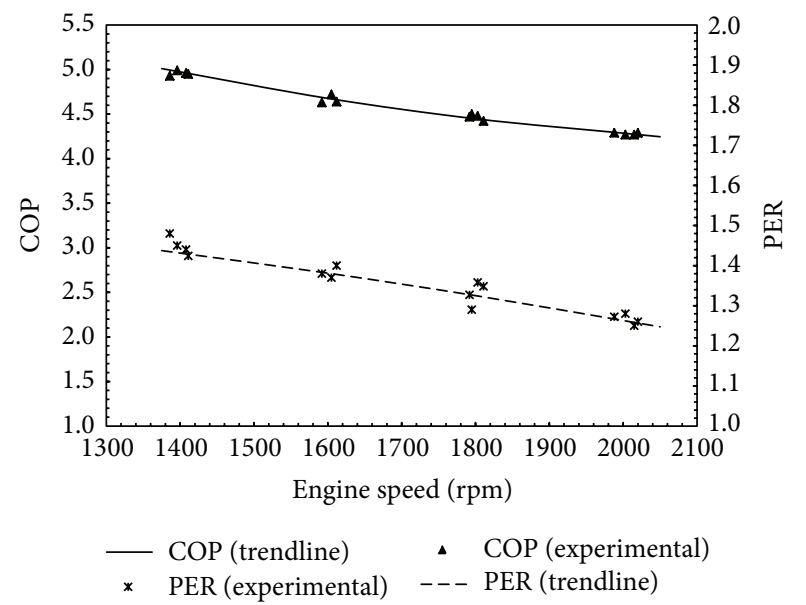

FIGURE 5: Heat pump COP and system PER versus engine speed.

heating capacity increased by $12 \%, 21 \%$, and $29 \%$, respectively, which was consistent with findings reported for a similar GEHP system in the literature [9]. On the other hand, the recovered waste heat increased by $14 \%, 34 \%$, and $60 \%$, respectively. This implied that more heat was recovered as the engine speed increased. It could be clearly seen in Figure 4. The fraction of the recovered waste heat with respect to the heating capacity increased from $42 \%$ to $53 \%$ as the engine speed increased from $1400 \mathrm{rpm}$ to $2000 \mathrm{rpm}$.

Figure 5 showed the variation of the heat pump COP and the system PER as the engine speed increased. Both the heat pump COP and the system PER decreased with the increase of engine speed, which was also consistent with the finding for a similar GEHP system reported in the literature [9]. The heat pump COP and the system PER decreased by $14 \%$ and $12 \%$, respectively, as engine speed increased from $1400 \mathrm{rpm}$ to $2000 \mathrm{rpm}$. This implied that the GEHP system could have perfect part-load performance. The reason is explained by the heat transfer areas of the condenser, evaporator, and exhaust 
TABLE 1: GEHP experimental parameters.

\begin{tabular}{|c|c|}
\hline Parameter & Value \\
\hline \multicolumn{2}{|l|}{ (1) The effect of engine speed experiment } \\
\hline Engine speed (r/min) & $1400,1600,1800$, and 2000 \\
\hline Ambient temperature $\left({ }^{\circ} \mathrm{C}\right)$ & 3 \\
\hline Condenser water flow rate $\left(\mathrm{m}^{3} / \mathrm{h}\right)$ & 8.53 \\
\hline Condenser water inlet temperature $\left({ }^{\circ} \mathrm{C}\right)$ & 40 \\
\hline \multicolumn{2}{|l|}{ (2) The effect of ambient temperature experiment } \\
\hline Engine speed (r/min) & 1800 \\
\hline Ambient temperature $\left({ }^{\circ} \mathrm{C}\right)$ & $3,7.2$, and 11.8 \\
\hline Condenser water flow rate $\left(\mathrm{m}^{3} / \mathrm{h}\right)$ & 8.53 \\
\hline Condenser water inlet temperature $\left({ }^{\circ} \mathrm{C}\right)$ & 40 \\
\hline \multicolumn{2}{|l|}{ (3) The effect of condenser water flow rate experiment } \\
\hline Engine speed (r/min) & 1800 \\
\hline Ambient temperature $\left({ }^{\circ} \mathrm{C}\right)$ & 3 \\
\hline Condenser water flow rate $\left(\mathrm{m}^{3} / \mathrm{h}\right)$ & $7.58,8.53$, and 9.47 \\
\hline Condenser water inlet temperature $\left({ }^{\circ} \mathrm{C}\right)$ & 40 \\
\hline \multicolumn{2}{|l|}{ (4) The effect of condenser water inlet temperature experiment } \\
\hline Engine speed (r/min) & 1800 \\
\hline Ambient temperature $\left({ }^{\circ} \mathrm{C}\right)$ & 3 \\
\hline Condenser water flow rate $\left(\mathrm{m}^{3} / \mathrm{h}\right)$ & 8.53 \\
\hline Condenser water inlet temperature $\left({ }^{\circ} \mathrm{C}\right)$ & 38,40 , and 42 \\
\hline Evaporation pressure (MPa) & $0.36 \sim 0.44$ \\
\hline Condensation pressure $(\mathrm{MPa})$ & $2.04 \sim 2.13$ \\
\hline Evaporation air inlet temperature $\left({ }^{\circ} \mathrm{C}\right)$ & 3 \\
\hline Waste heat exchanger water inlet temperature $\left({ }^{\circ} \mathrm{C}\right)$ & $71.7 \sim 72.9$ \\
\hline Waste heat exchanger R407c inlet temperature $\left({ }^{\circ} \mathrm{C}\right)$ & $-1.9 \sim-5.2$ \\
\hline $\begin{array}{l}\text { Exhaust gas heat exchanger exhaust gas inlet temperature }\left({ }^{\circ} \mathrm{C}\right) \\
\text { Cylinder heat exchanger exhaust gas outlet temperature }\left({ }^{\circ} \mathrm{C}\right)\end{array}$ & $165.8 \sim 185.9$ \\
\hline Exhaust gas heat exchanger exhaust gas outlet temperature $\left({ }^{\circ} \mathrm{C}\right)$ & $49.0 \sim 51.3$ \\
\hline Exhaust gas heat exchanger water inlet temperature $\left({ }^{\circ} \mathrm{C}\right)$ & $65.2 \sim 67.5$ \\
\hline $\begin{array}{l}\text { Exhaust gas heat exchanger exhaust gas outlet temperature }\left({ }^{\circ} \mathrm{C}\right) \\
\text { Cylinder heat exchanger exhaust gas inlet temperature }\left({ }^{\circ} \mathrm{C}\right)\end{array}$ & $67.7 \sim 69.1$ \\
\hline Cylinder heat exchanger exhaust gas outlet temperature $\left({ }^{\circ} \mathrm{C}\right)$ & $72.5 \sim 72.8$ \\
\hline
\end{tabular}

heat exchangers. These heat transfer areas were designed based on the nominal speed of the GEHP system (1800 rpm). These heat transfer areas were larger than those designed for lower speeds, which would reduce the fuel consumption and hence improve the system performance at low speeds. For the high speed, the heat transfer area is relatively smaller in comparison to the standard design and hence the heat transfer rate is not sufficient for the large capacity. Therefore, both the engine and heat pump performance drop at high engine speed.

4.2. Effect of Ambient Temperature. The effect of ambient temperature on the GEHP system performance was shown in Figures 6-8. As shown in Figure 6, the heating capacity increased by $20 \%$ and $25 \%$, respectively, as the ambient temperature increased from $3^{\circ} \mathrm{C}$ to $7.2^{\circ} \mathrm{C}$ and $11.8^{\circ} \mathrm{C}$. This was consistent with that reported for the standard heat pump system. As the ambient temperature increased, the evaporation temperature went up and hence the refrigerant mass flow rate of the heat pump increased, which would result in the increase of the heating capacity.

However, Figure 6 showed that the variation of the recovered waste heat was less than $5 \%$ as the ambient temperature increased from $3^{\circ} \mathrm{C}$ to $11.8^{\circ} \mathrm{C}$. This is negligible when taking into consideration the experimental measurement error. As the ambient temperature increased, the evaporation temperature went up and the refrigerant absorbed more energy in the evaporator, while less energy was absorbed by the refrigerant in the waste heat recovery exchanger. Therefore, the recovered waste heat was almost the same although the heating capacity increased. This led to the small decrease in the fraction of the recovered waste heat with respect to the heating capacity, with the increase in ambient temperature, as shown in Figure 7.

Figure 8 indicated the variation of the heat pump COP and the GEHP system PER at different ambient temperatures. The heat pump COP increased by $7 \%$ and $22 \%$ as the ambient 


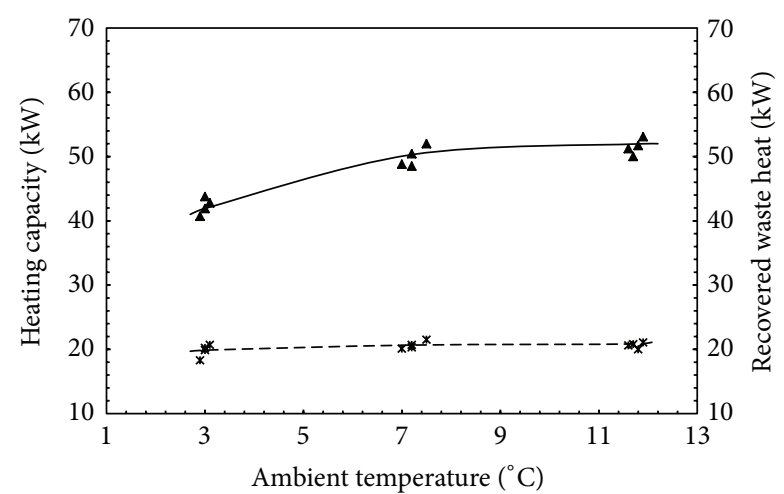

- Heating capacity (experimental)

_ Heating capacity (trendline)

* Recovered waste heat (experimental)

- - - Recovered waste heat (trendline)

Figure 6: Heating capacity and recovered waste heat versus ambient temperature.

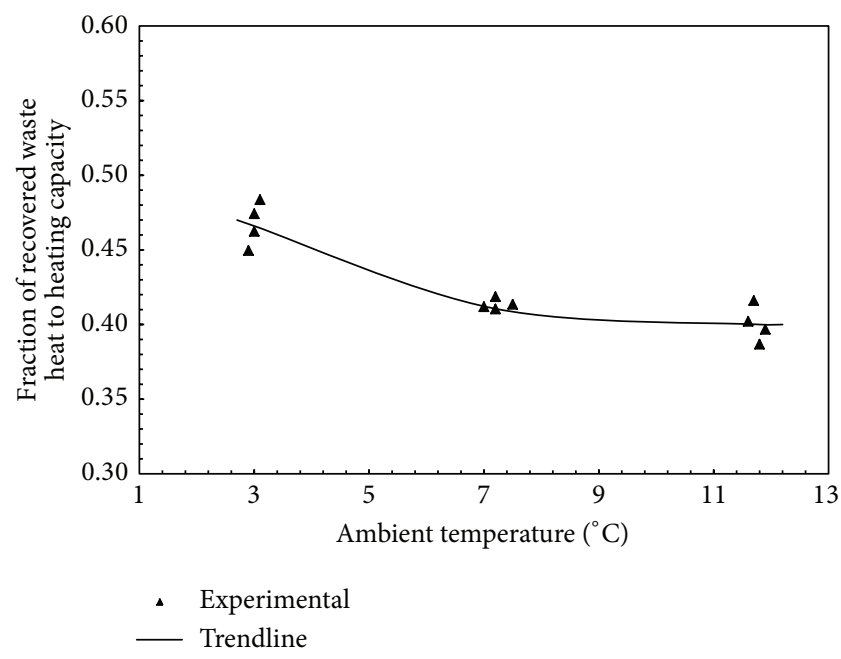

FIGURE 7: Fraction of recovered waste heat to heating capacity versus ambient temperature.

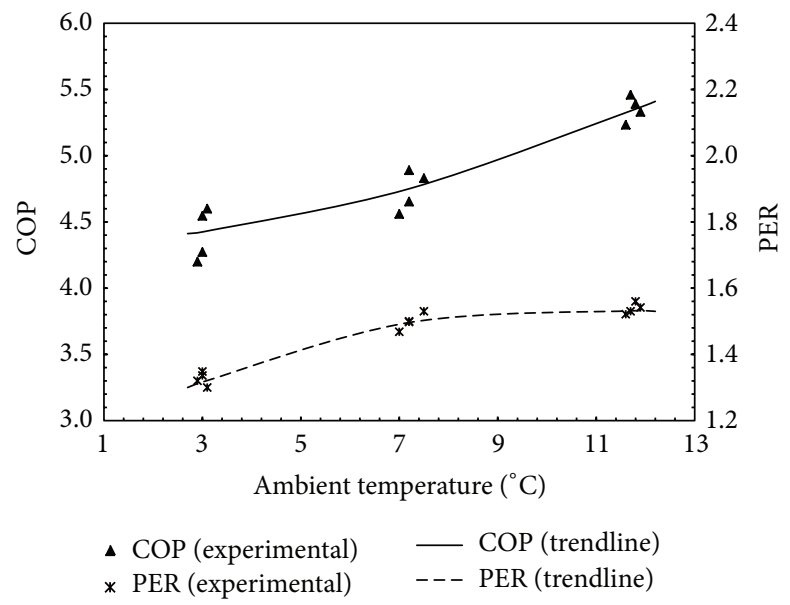

FIGURE 8: Heat pump COP and system PER versus ambient temperature.

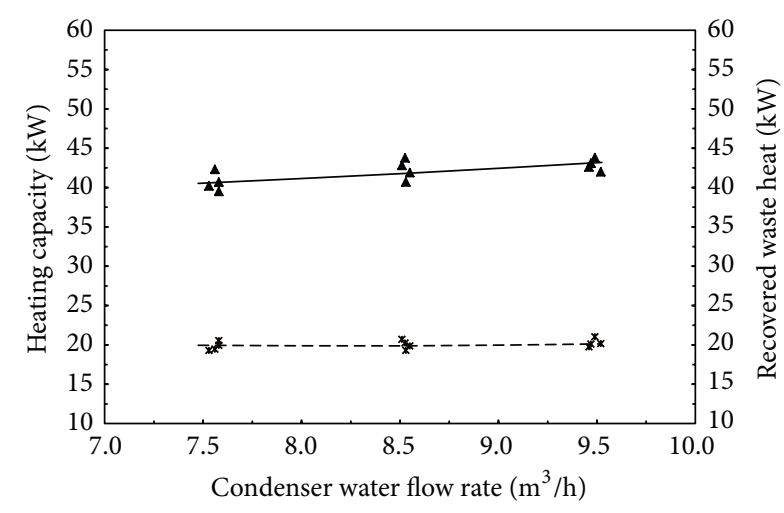

\ Heating capacity (experimental)

* Recovered waste heat (experimental)

- Heating capacity (trendline)

--- Recovered waste heat (trendline)

FIGURE 9: Heating capacity and recovered waste heat versus condenser water flow rate.

temperature increased from $3^{\circ} \mathrm{C}$ to $7.2^{\circ} \mathrm{C}$ and $11.8^{\circ} \mathrm{C}$. This can be easily understood from the standard heat pump system. The increase of the ambient temperature led to the increase of the evaporation temperature and pressure which improved the heat pump COP. On the other hand, the GEHP system PER increased by $13 \%$ as the ambient temperature increased from $3^{\circ} \mathrm{C}$ to $7.2^{\circ} \mathrm{C}$, while it only increased by $3 \%$ when the ambient temperature increased from $7.2^{\circ} \mathrm{C}$ to $11.8^{\circ} \mathrm{C}$. This was due to the waste heat recovery. With increasing ambient temperature, the fraction of recovered waste heat decreased with respect to heating capacity. However, the compressor power increased with the increase in ambient temperature, due to an increase in the refrigerant flow rate. At the same time, the engine efficiency dropped as the ambient temperature increased. The engine fuel consumption was then increased. Therefore, the influence of the ambient temperature on the system PER became relatively smaller at the high ambient temperature. This was consistent with the theoretical finding for a gas engine driven air to water heat pump reported in the literature [2].

4.3. Effect of Condenser Water Flow Rate. Figures 9-11 showed the dependency of the GEHP system performance upon the condenser water flow rate, with an engine speed of $1800 \mathrm{rpm}$, ambient temperature of $3^{\circ} \mathrm{C}$, and condenser water inlet temperature of $40^{\circ} \mathrm{C}$. Measured heating capacity and recovered waste heat against the condenser water flow rate were presented in Figure 9. The influence of the condenser water flow rate on both heating capacity and recovered waste heat was insignificant at the studied flow rate range when considering the measurement error. The heating capacity and recovered waste heat only increased by $6 \%$ and $1.2 \%$, respectively, as the condenser water flow rate increased from $7.58 \mathrm{~m}^{3} / \mathrm{h}$ to $9.47 \mathrm{~m}^{3} / \mathrm{h}$. This was consistent with the finding for a small GEHP system reported in the literature [9]. The increase of condenser water flow rate slightly lowered the 


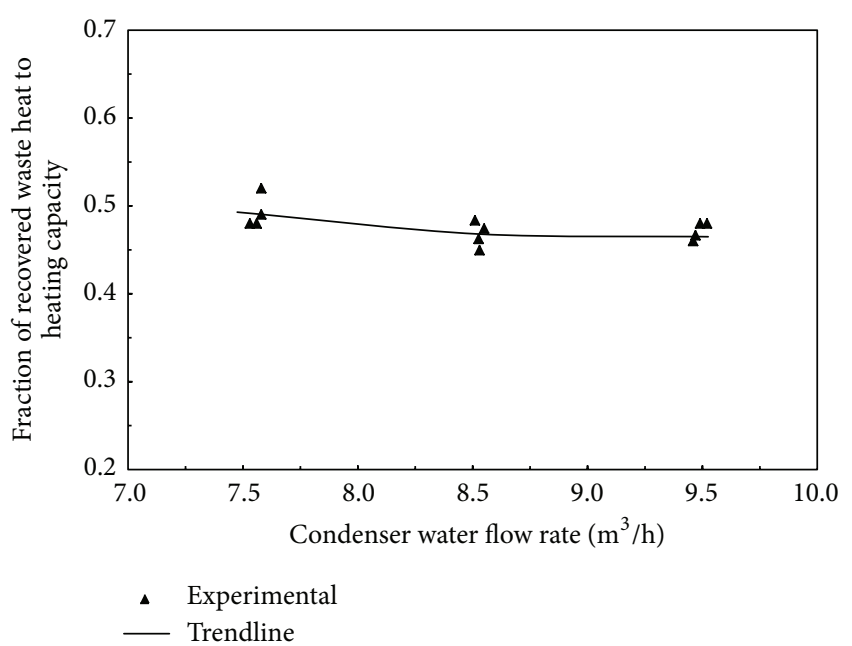

FIGURE 10: Fraction of recovered waste heat to heating capacity versus condenser water flow rate.

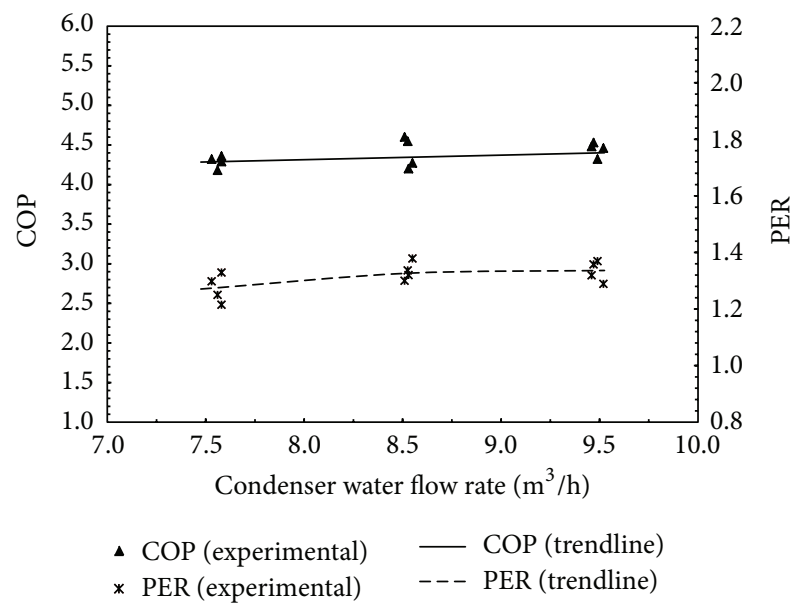

FIgURE 11: COP and PER versus condenser water flow rate.

heat transfer temperature difference and the heat losses of the condenser. The condenser water outlet temperature went down and the heating capacity of the heat pump increased slightly. However, the recovered waste heat barely changed in the experimental process. This explained the decrease in the fraction of recovered waste heat to total heating capacity, as shown in Figure 10.

Furthermore, when the condenser water flow rate increased, the overall refrigerant condensing temperature and pressure dropped, and hence the compressor power consumption reduced. This led to an increase of the heat pump COP, as shown in Figure 11. In the experimental process, it was also found that the fuel consumptions dropped slightly due to drop of the compressor power. Therefore, the system PER increased by $6 \%$ upon increasing the condenser water flow rate from $7.58 \mathrm{~m}^{3} / \mathrm{h}$ to $9.47 \mathrm{~m}^{3} / \mathrm{h}$.

4.4. Effect of Condenser Water Inlet Temperature. Performance characteristics of the GEHP system as a function

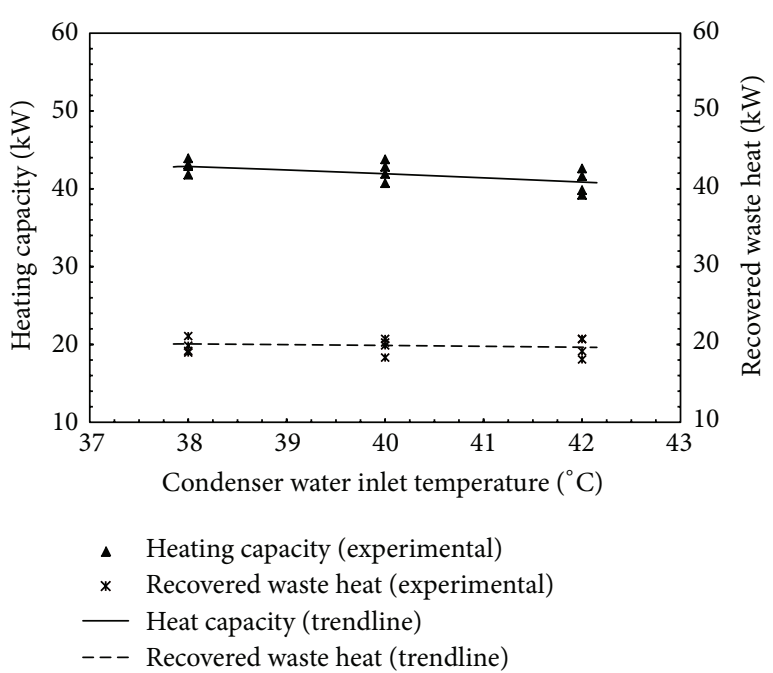

FIGURE 12: Heating capacity and recovered waste heat versus condenser water inlet temperature.

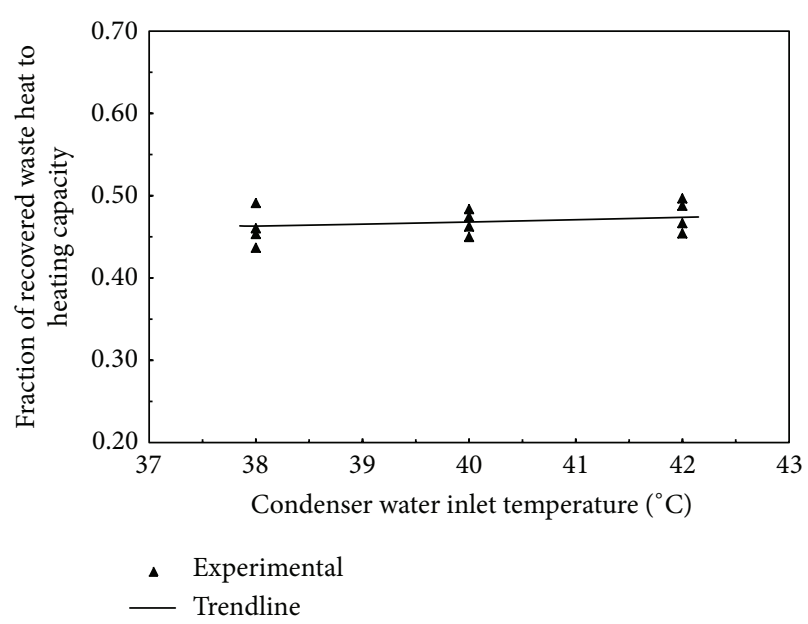

FIGURE 13: Fraction of recovered waste heat to heating capacity versus condenser water inlet temperature.

of condenser water inlet temperature were presented in Figures 12-14, with an ambient temperature of $3^{\circ} \mathrm{C}$, condenser water flow rate of $8.5 \mathrm{~m}^{3} / \mathrm{h}$, and engine speed of $1800 \mathrm{rpm}$. Figure 12 illustrated that the heating capacity and recovered waste heat decreased as the condenser water inlet temperature increased from 38 to $42^{\circ} \mathrm{C}$, which was consistent with the finding reported in the literature [14]. However, the rate of decrease in the heating capacity and recovered waste heat was very small. The fraction of the recovered engine waste heat to the heating capacity remained unchanged with the increase in condenser water inlet temperature, as shown in Figure 13.

Figure 14 showed that the heat pump COP and system PER decreased by $4 \%$ and $8.5 \%$, respectively, as the condenser water inlet temperature increased from 38 to $42^{\circ} \mathrm{C}$. This trend was consistent with the common practice for heat pumps. As the condenser water inlet temperature increased, the refrigerant condensing temperature and condensing pressure went 


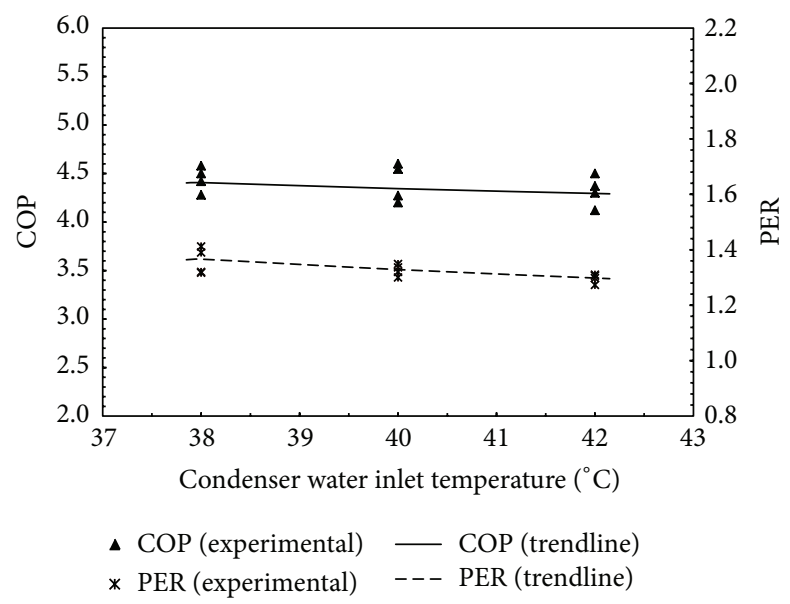

FIGURE 14: COP and PER versus condenser water inlet temperature.

up. Hence the compressor power consumption increased due to the large compression ratio, which led to an increase in engine fuel consumption. Therefore, both the COP and PER reduced.

Furthermore, it was observed that the heat pump COP decreasing rate is smaller than the system PER decreasing rate. This is explained by the heat recovery. When condensing pressure increased, the engine fuel consumption increased, while the recovered waste heat did not increase accordingly. Hence the engine efficiency decreased and then the GEHP system PER dropped faster than the heat pump COP.

\section{Conclusions}

This paper experimentally investigated the performance characteristics of a GEHP system over a wide range of operating conditions. An experimental test rig was built for this purpose. The effect of the engine speed, ambient temperature, condenser water flow rate, and condenser water inlet temperature on the GEHP system performance was analyzed. According to the trendline obtained from the second order polynomial fit on the experimental data, it was found that the engine speed and ambient temperature had a large influence on the system COP and PER, while the condenser water flow rate and condenser water inlet temperature had only a small effect on the system COP and PER. The experimental results showed that

(1) the recovered engine waste heat was about $40-50 \%$ of the total GEHP system heating capacity;

(2) the heat pump COP and system PER decreased by $14 \%$ and $12 \%$, respectively, as the engine speed increased from $1400 \mathrm{rpm}$ to $2000 \mathrm{rpm}$; this also implied that the GEHP system could have a good part-load performance;

(3) the heat pump COP and the GEHP system PER increased by $22 \%$ and $16 \%$, respectively, upon the ambient temperature increasing from 3 to $12^{\circ} \mathrm{C}$; it was also found that the GEHP system PER would not be affected by the ambient temperature when it increased to a certain level;

(4) the condenser water flow rate and inlet temperature had insignificant influence on the GEHP system performance over the studied range.

\section{Conflict of Interests}

The authors declare that there is no conflict of interests regarding the publication of this paper.

\section{References}

[1] S. Garimella, "Innovations in energy efficient and environmentally friendly space-conditioning systems," Energy, vol. 28, no. 15, pp. 1593-1614, 2003.

[2] R. R. Zhang, X. S. Lu, S. Z. Li, W. S. Lin, and A. Z. Gu, "Analysis on the heating performance of a gas engine driven air to water heat pump based on a steady-state model," Energy Conversion and Management, vol. 46, no. 11-12, pp. 1714-1730, 2005.

[3] Y. Shin, H. Yang, C. S. Tae, C. Y. Jang, and S. Cho, "Dynamics modeling of a gas engine-driven heat pump in cooling mode," Journal of Mechanical Science and Technology, vol. 20, no. 2, pp. 278-285, 2006.

[4] Z. Yang, H. Zhao, and Z. Fang, "Modeling and dynamic control simulation of unitary gas engine driven heat pump," Energy Conversion and Management, vol. 48, no. 12, pp. 3146-3153, 2007.

[5] S. Li, W. Zhang, R. Zhang, D. Lv, and Z. Huang, "Cascade fuzzy control for gas engine driven heat pump," Energy Conversion and Management, vol. 46, no. 11-12, pp. 1757-1766, 2005.

[6] Z. Xu and Z. Yang, "Saving energy in the heat-pump air conditioning system driven by gas engine," Energy and Buildings, vol. 41, no. 2, pp. 206-211, 2009.

[7] S. Sanaye and M. Chahartaghi, "Thermal modeling and operating tests for the gas engine-driven heat pump systems," Energy, vol. 35, no. 1, pp. 351-363, 2010.

[8] S. Sanaye, M. A. Meybodi, and M. Chahartaghi, "Modeling and economic analysis of gas engine heat pumps for residential and commercial buildings in various climate regions of Iran," Energy and Buildings, vol. 42, no. 7, pp. 1129-1138, 2010.

[9] Z. Yang, W.-B. Wang, and X. Wu, "Thermal modeling and operating tests for a gas-engine driven heat pump working as a water heater in winter," Energy and Buildings, vol. 58, pp. 219226, 2013.

[10] J. Patel, H. I. Henderson Jr., and M. Collins, "Comparing gasengine cooling systems," ASHRAE Journal, vol. 40, no. 3, pp. 6570, 1998.

[11] Z. Yang, H. Cheng, S. G. Zhang, and Y. B. Xie, "Experimental research of a compressive heat pump air-condition system driven by gas engine," Journal of Engineering Thermophysics, vol. 24, no. 6, pp. 920-922, 2003.

[12] R. Lazzarin and M. Noro, "District heating and gas engine heat pump: economic analysis based on a case study," Applied Thermal Engineering, vol. 26, no. 2-3, pp. 193-199, 2006.

[13] E. Elgendy and J. Schmidt, "Experimental study of gas engine driven air to water heat pump in cooling mode," Energy, vol. 35, no. 6, pp. 2461-2467, 2010. 
[14] E. Elgendy, J. Schmidt, A. Khalil, and M. Fatouh, "Performance of a gas engine driven heat pump for hot water supply systems," Energy, vol. 36, no. 5, pp. 2883-2889, 2011.

[15] J. Brenn, P. Soltic, and C. Bach, "Comparison of natural gas driven heat pumps and electrically driven heat pumps with conventional systems for building heating purposes," Energy and Buildings, vol. 42, no. 6, pp. 904-908, 2010. 


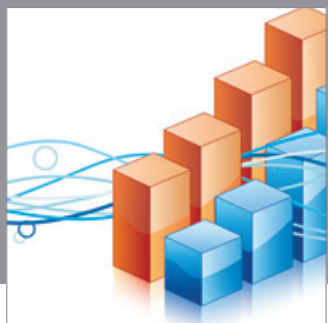

Advances in

Operations Research

mansans

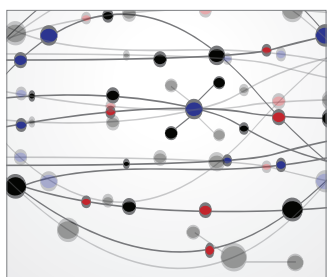

The Scientific World Journal
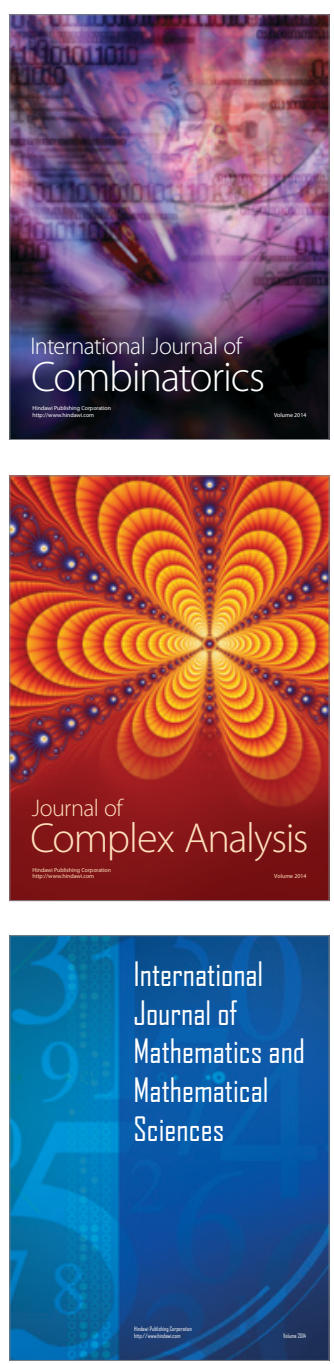
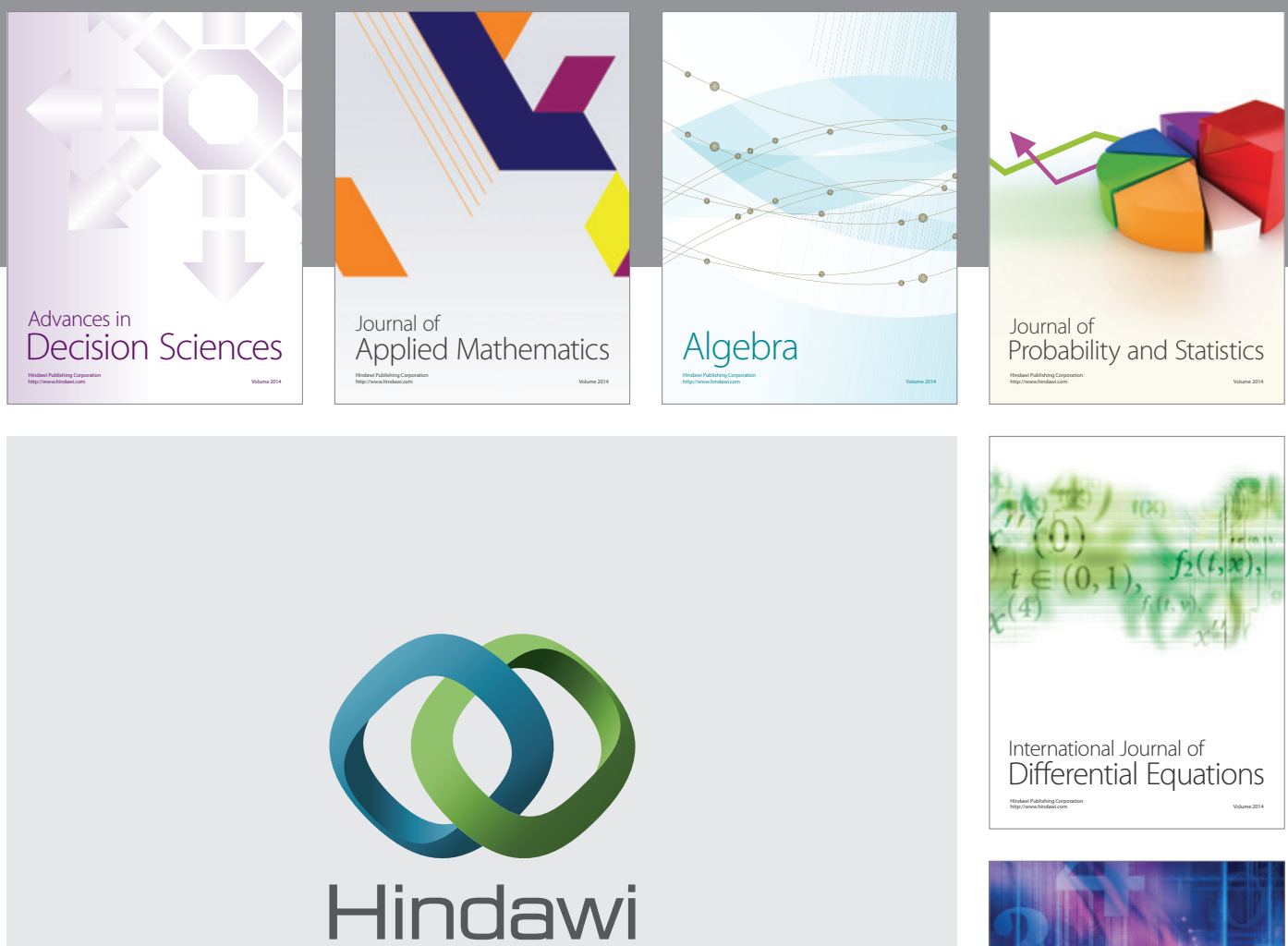

Submit your manuscripts at http://www.hindawi.com
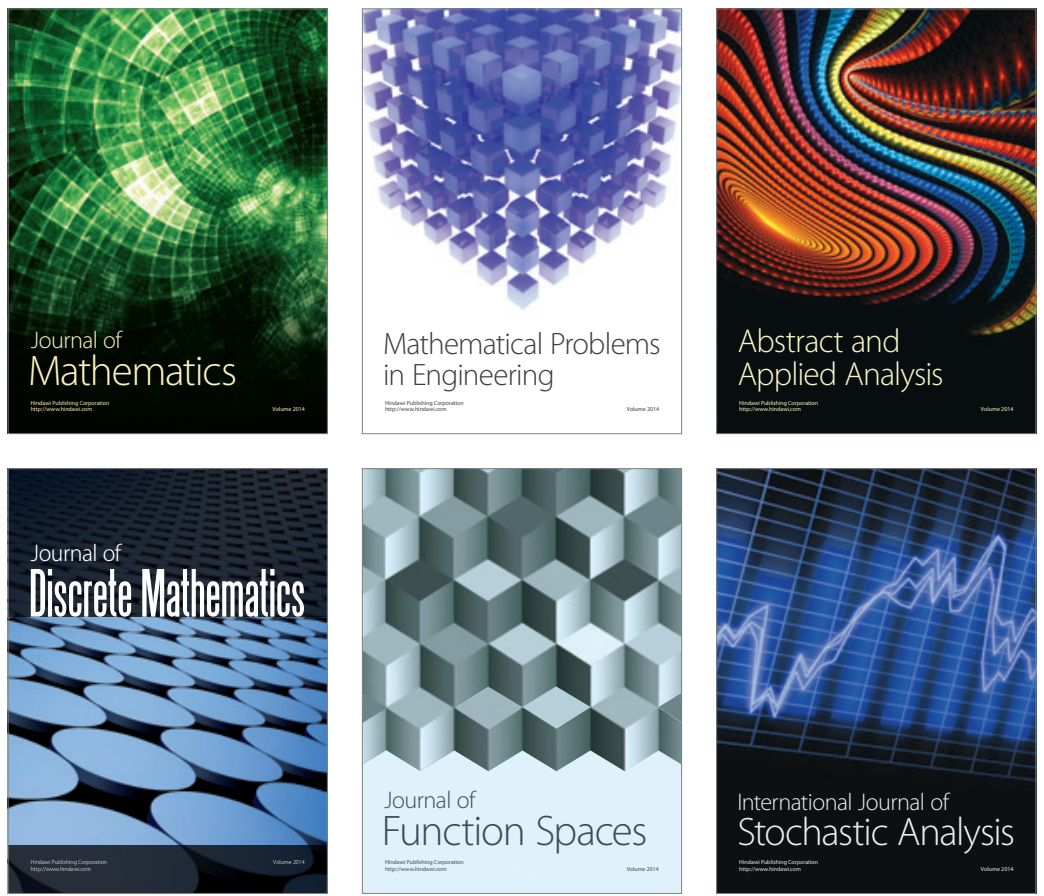

Journal of

Function Spaces

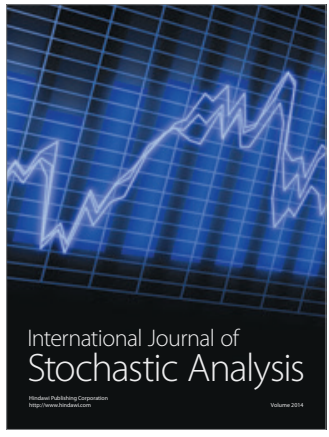

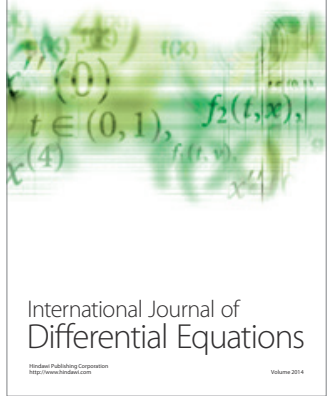
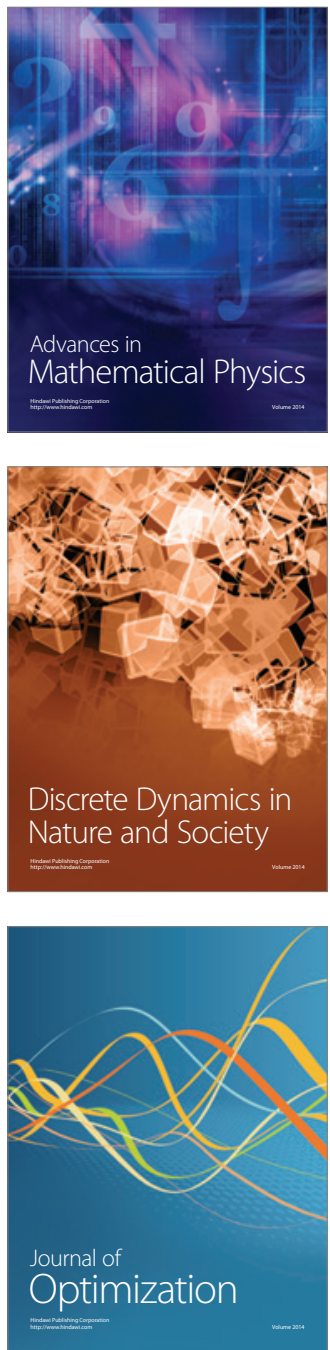